\section{Hot-water Dips Extend the Shelf Life of Fresh Broccoli}

\author{
Charles F. Forney ${ }^{1}$ \\ Agriculture and Agri-Food Canada, Kentville Research Centre, 32 Main \\ Street, Kentville, N.S. B4N 1J5, Canada
}

Additional index words. Heat treatment, senescence, yellowing, hue angle, weight loss, decay, off-odor, quality, Brassica oleracea

\begin{abstract}
Freshly harvested heads of 'Cruiser' or 'Paragon' broccoli (Brassica oleracea $\mathbf{L}$. Italica group) were heated by immersing in water at 42, 45, 48, 50, or $52 \mathrm{C}$. Immersion times were decreased as treatment temperatures were increased and ranged from 20 to 40 minutes at $42 \mathrm{C}$ to 1 to 3 minutes at 52C. Control heads, dipped in $25 \mathrm{C}$ water for 0 , 10, or 40 minutes, began to turn yellow after $\approx 3$ days storage at $20 \mathrm{C}$ and $80 \%$ to $90 \%$ relative humidity. Immersion in $42 \mathrm{C}$ water delayed yellowing by 1 or 2 days; immersion in 45, 48, 50, or 52C prevented yellowing for $\leq 7$ days. Water loss of broccoli during storage at 20C increased by $\leq 1 \%$ per day by some hot-water treatments. Immersion in hot water decreased the incidence of decay during storage at $20 \mathrm{C}$. Immersion in 50 or $52 \mathrm{C}$ water for 2 minutes was most effective in controlling decay development. Broccoli immersed in 52C water for $\mathbf{3}$ minutes had a distinct off-odor. Control and treated broccoli held at $0 \mathrm{C}$ for $\mathbf{8}$ days following hot-water dips were similar in quality. Yellowing of heat-treated broccoli was inhibited when broccoli was warmed to $20 \mathrm{C}$ following storage at $0 \mathrm{C}$. Hot-water treatments also delayed senescence at $20 \mathrm{C}$ when broccoli was treated following 3 weeks of storage at $0 \mathrm{C}$. Immersion of broccoli in $50 \mathrm{C}$ water for 2 minutes was the most effective treatment for reducing yellowing and decay while not inducing off-odors or accelerating weight loss.
\end{abstract}

Broccoli is a highly perishable fresh vegetable. When held at ambient temperatures, broccoli will yellow and become unmarketable in 1 to 3 days (Gnanasekharan et al., 1992; Wang and Hruschka, 1977). Refrigeration is the primary means of maintaining broccoli quality and reducing the rate of senescence. Broccoli held at $2.5 \mathrm{C}$ will be in good condition after 3 weeks of storage (Ryall and Lipton, 1979). Controlled-atmosphere storage or modified-atmosphere packaging can also extend the storage life of broccoli at nonoptimal temperatures (Barth et al., 1993; Lipton and Harris, 1974). Atmospheres enriched with $10 \%$ $\mathrm{CO}_{2}$ can retard yellowing and double the storage life of broccoli held between 5 and 20C. However, atmosphere modification requires specialized storage facilities or packaging, and the beneficial effect is lost when the broccoli is removed.

Heat treatments can alter senescence of fruit by affecting the rates of softening, chlorophyll loss, ethylene synthesis, respiration, and protein synthesis (Paull, 1990). Kazami et al. (1991a) reported that dipping broccoli in $45 \mathrm{C}$ water for $14 \mathrm{~min}$ was effective in delaying

Received for publication 20 Dec. 1994. Accepted for publication 19 May 1995. Contribution no. 2142. I thank K.B. McRae (statistician) for advice on experiment planning, statistical analysis, and presentation of results; Peg Dixon for technical assistance; and Bruce Rand (Randsland Farms) for his generous donation of broccoli. The cost of publishing this paper was defrayed in part by the payment of page charges. Under postal regulations, this paper therefore must be hereby marked advertisement solely to indicate this fact.

${ }^{1}$ Storage Physiologist. yellowing for 2 to 3 days at 20C. Immersion in hot water also slowed the loss of soluble proteins and L-ascorbic acid and reduced the rate of respiration and ethylene production (Kazami et al., 1991b). Kazami et al. (1991a, 1991b) did on other quality factors, such as water loss, decay, or aroma. My objective was to identify optimum treatment times and temperatures to maximize storage life of fresh broccoli.

\section{Material and Methods}

Plant materials. 'Cruiser' or 'Paragon' broccoli heads were obtained on the day of harvest from a commercial packinghouse. Heads were trimmed to 100 to $120 \mathrm{~mm}$ long, and only heads free of visible decay were used. Heads were weighed and evaluated for color and quality before treatment.

Heat treatments. The duration plant tissues tolerate exposure to temperatures $>45 \mathrm{C}$ decreases exponentially as exposure temperature increases (Couey, 1989). Kazami et al. (1991a) reported that hot-water dips of $45 \mathrm{C}$ for $14 \mathrm{~min}$ or $48 \mathrm{C}$ for $6 \mathrm{~min}$ were optimum for minimizing chlorophyll loss from fresh broccoli held at 20C. Plotting Kazami's optimum time and temperature combinations using a log scale for time allowed exposure to be extrapolated from 42 to $52 \mathrm{C}$; these combinations were designated as medium. Short and long exposures then were chosen to bracket the medium exposure at each temperature (Table 1). Exposures for the 25C controls were chosen to bracket the extreme dip times and account for any effect of the water dip. Three heads of broccoli for each time-temperature combination were placed into a stainless-steel not evaluate the effect of hot-water immersion cage with a mesh lid. The cage ensured complete immersion of the broccoli while allowing water to circulate around each head. The cage was placed into a 35-liter insulated container filled with 25 liters of distilled water. Temperature of the water was controlled by an immersion circulator (model E8; Haake, Berlin, Germany). Broccoli temperature was monitored in initial experiments by placing a thermocouple in the center of the stem. Pulp temperature rose rapidly following water immersion and was within $1 \mathrm{C}$ of the water temperature in $<1 \mathrm{~min}$. Following treatment, broccoli heads were centrifuged at $500 \times g$ for 2 min to remove excess water in a centrifuge (model C50; International Equipment Co., Boston), equipped with a stainless-steel cage rotor (21 $\mathrm{cm}$ in diameter).

Storage conditions. Treated broccoli was held at $20 \mathrm{C}$ and $80 \%$ to $90 \%$ relative humidity in darkness immediately following treatment. In separate experiments, 'Paragon' broccoli was placed in perforated polyethylene bags and held at 0C for 8 days following heat treatment or 3 weeks before heat treatment. Following these $0 \mathrm{C}$ holding periods, broccoli was evaluated during 1 week at $20 \mathrm{C}$.

Quality evaluation. Color, weight loss, turgidity, decay, and odor evaluations were made on the same heads before broccoli heads were placed into storage and each day during storage at $20 \mathrm{C}$ for 1 week. Commission Internationale de l'Eclairage $\mathrm{L}^{*}\left(\mathrm{~L}\right.$ value), $\mathrm{C}^{*}$ (chroma), and $\mathrm{H}^{\circ}$ (hue angle) were determined with a chromameter (model CR-200; Minolta, Ramsey, N.J.) equipped with an 8-mm measuring aperture and calibrated with a white standard tile. Measurements of flower buds were taken at the center and four locations equally spaced around each head and averaged. Heads were weighed daily to determine fresh weight (FW) loss. Subjective rankings of flower bud yellowing, stem turgidity, flower bud decay, and odor were made using the criteria of Wang and Hruschka (1977). Traits were rated on the following scales: yellowing, $0=$ no yellow (dark green), $10=$ completely yellow; turgidity, $0=$ limp and shriveled, $10=$ turgid; decay, fungal spotting, and bacterial soft rot, $0=$ none, $10=$ leaky mass; and odor, $0=$ normal, $10=$ nauseating .

Data analysis. Daily measurements of color and other quality attributes for each broccoli head were fitted to straight lines using linear regression. Slopes of these lines, representing rates of change per day, were analyzed using analysis of variance (ANOVA) in Genstat 5 (Payne et al., 1993). In the main experiment, slopes were analyzed using a split-plot design

Table 1. Temperature and time combinations used to treat fresh broccoli.

\begin{tabular}{lccc}
\hline \hline $\begin{array}{l}\text { Temp } \\
\left({ }^{\circ} \mathrm{C}\right)\end{array}$ & \multicolumn{3}{c}{ Time (min) } \\
\cline { 2 - 4 } & Short & Medium & Long \\
\hline 25 & 0 & 10 & 40 \\
42 & 20 & 30 & 40 \\
45 & 10 & 15 & 20 \\
48 & 4 & 6 & 8 \\
50 & 2 & 4 & 6 \\
52 & 1 & 2 & 3 \\
\hline
\end{tabular}

HortScience, Vol. 30(5), August 1995 
Table 2. Mean squares for mean daily change in quality characteristics of 'Cruiser' and 'Paragon' broccoli held at 20C for 7 days following immersion in 25, 42 , $45,48,50$, or $52 \mathrm{C}$ water for various durations.

\begin{tabular}{|c|c|c|c|c|c|c|c|c|c|}
\hline \multirow[b]{2}{*}{ Source } & \multirow[b]{2}{*}{$\mathrm{df}^{\mathrm{z}}$} & \multicolumn{8}{|c|}{ Mean square } \\
\hline & & Yellowing & $\mathrm{L}$ value & Chroma & Hue angle & \% Fresh wt loss & Turgidity ${ }^{2}$ & Decay & Odor \\
\hline Cultivar (Cv) & 1 & 0.84 & 0.52 & 8.09 & 17.27 & $209.54^{*}$ & 87.01 & 1.88 & $\overline{---}$ \\
\hline Error & 2 & 5.38 & 2.22 & 10.19 & 22.25 & 3.68 & 158.00 & 21.49 & \\
\hline Temperature (Tp) & 5 & $7.42^{* * * *}$ & $22.14^{* * * *}$ & $27.98^{* * * *}$ & $201.11^{* * * *}$ & $13.07^{* * * *}$ & $80.45^{* * * *}$ & $0.74^{* * * *}$ & $1.07^{* * * *}$ \\
\hline Time $(\mathrm{Tm})$ & 2 & $1.27^{* * * *}$ & $5.19^{* * * *}$ & $2.77^{*}$ & $29.40^{* * * *}$ & $3.30^{*}$ & 0.36 & $1.17^{* * *}$ & $1.32^{* * * *}$ \\
\hline $\mathrm{Tp} \times \mathrm{Tm}$ & 10 & $0.17^{* * * *}$ & 0.49 & 0.7 & 2.12 & 1.46 & $22.83^{* * * *}$ & 0.22 & 0.14 \\
\hline $\mathrm{Tp} \times \mathrm{Cv}$ & 2 & $0.21^{* *}$ & $4.00^{* * * *}$ & $18.01^{* * * *}$ & $9.35^{* * *}$ & $6.90^{* * * *}$ & $48.75^{* * * *}$ & $0.70^{* * * *}$ & --- \\
\hline $\mathrm{Tm} \times \mathrm{Cv}$ & 2 & 0.09 & 0.07 & 0.12 & $6.78^{*}$ & 1.83 & 0.57 & $0.61^{*}$ & --- \\
\hline $\mathrm{Tp} \times \mathrm{Tm} \times \mathrm{Cv}$ & 10 & $0.17^{* * *}$ & 0.46 & 0.37 & 1.67 & $2.68^{* * * *}$ & $28.34^{* * * *}$ & 0.17 & --- \\
\hline Error & $\begin{array}{l}178 \\
(89)^{y}\end{array}$ & 0.05 & 0.52 & 0.88 & 1.90 & 0.84 & 6.17 & 0.15 & 0.14 \\
\hline
\end{tabular}

${ }^{\mathrm{z}}$ Mean square $\times 10^{2}$.

$\mathrm{y}$ df for odor.

${ }^{*, * *, * * *}$ Significant at $P \leq 0.05,0.01$, or 0.001 , respectively.

with two replications. The two cultivars were the main blocks, and the subblocks consisted of a $3 \times 6$ factorial with time and temperature treatments (Table 1). Within each treatment of each subblock, three heads of broccoli were analyzed. Only 'Paragon' was evaluated for odor. In the additional experiments in which 'Paragon' broccoli was held at $0 \mathrm{C}$ before evaluation at 20C, slopes were analyzed using a completely randomized design using the same $3 \times 6$ factorial.

\section{Results}

Cultivar effects. Cultivar had no significant main effect on any of the quality attributes, except for FW loss (Table 2). However, there was a cultivar $\times$ treatment temperature interaction for all criteria. The rate of yellowing of control 'Paragon', treated at 25C, exceeded that for 'Cruiser'. All heat treatments reduced the rate of yellowing in both cultivars, and the difference between cultivars, observed in the controls, was absent in treated broccoli. An ANOVA on the data from just the heat-treated broccoli, excluding the $25 \mathrm{C}$ controls, showed no significant cultivar $x$ temperature interaction for any of the quality attributes.

Broccoli color. Heat treatments inhibited yellowing in fresh broccoli (Table 2, Fig. 1) The $25 \mathrm{C}$ control broccoli had a daily increase in yellowing score of 1.6 , and after $\approx 3$ days at $20 \mathrm{C}$, it had an average score of 4.8 , indicating "slight yellowing." All of the heat-treated broccoli yellowed more slowly and remained green. Of the treatment temperatures tested, $42 \mathrm{C}$ was least effective; 45 to $52 \mathrm{C}$ reduced the rate of yellowing similarly. As exposures increased at a given temperature, rates of yellowing decreased. The most effective treatments to reduce yellowing were the long exposures to 48,50 , and $52 \mathrm{C}$.

The inhibition of yellowing was reflected in the small daily change in L value, chroma, and hue angle in treated broccoli (Fig. 2). Hue angle gave the best indication of greenness and averaged $132.5^{\circ}$ in freshly harvested broccoli. In previous work, a hue angle value of $106^{\circ}$ correlated with visual yellowing scores of 4 , indicating a yellowing of the broccoli (data not shown). As with yellowing, hue angle values of control heads declined to unac- ceptable values of $\approx 110^{\circ}$ after 3 days. Immersion in hot water reduced this rate of decline. Treatments most effective in reducing the decline in hue angle corresponded with subjective yellowing ratings. The average initial $\mathrm{L}$ and chroma values of nontreated broccoli were 42.0 and 16.4, respectively. Both of these values increased 2 to 3 units per day in control broccoli, but in broccoli treated at temperatures ranging from 45 to $52 \mathrm{C}$, this increase was reduced to less than one unit per day.

Fresh weight loss and turgidity. The rate of fresh weight loss of heat-treated broccoli was as much as $1 \%$ per day more in treated broccoli than in the controls (Fig. 3). Rates of fresh weight loss of control broccoli averaged $\approx 4.6 \%$ per day, and some of the heat-treated broccoli lost as much as $6.0 \%$ per day. Rates of water loss tended to be higher with low-temperature heat treatments and may relate to longer immersion times. Subjective scores of turgidity corresponded with changes in fresh weight.

Decay. Decay that developed on the broccoli flower buds was a combination of fungal spotting and bacterial rots. Decay scores decreased with increasing treatment temperature but increased with increasing treatment time at a given temperature (Fig. 3). Rates of decay were lowest in the $52 \mathrm{C}-2 \mathrm{~min}, 52 \mathrm{C}-1 \mathrm{~min}$, $50 \mathrm{C}-2 \mathrm{~min}$, and $48 \mathrm{C}-4 \mathrm{~min}$ treatment combinations. None of the heat treatments increased the rate of decay of flower buds over that of the controls.

Odor. "Green floral" off-odors were induced by high temperatures and long exposures (Fig. 3). Off-odor increased more rapidly as treatment temperatures and exposure times increased. Broccoli treated at 48 to $52 \mathrm{C}$ combined with medium and long exposure times developed off-odors more rapidly than controls. Off-odor was most noticeable in the $52 \mathrm{C}-3$ min treatment combination and was present immediately following treatment.

Refrigerated storage. When broccoli was stored for 8 days at $0 \mathrm{C}$ following heat treatment, there was no difference in the yellowing, turgidity, or decay of control and treated heads. However, when heads were held an additional week at 20C, quality of heads changed in a manner similar to heads held at 20C immediately after treatment (data not shown).

Heat treatments were still effective in in-

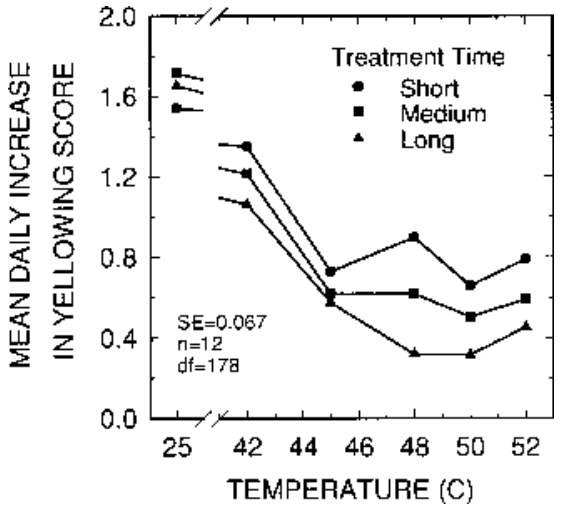

Fig. 1. Mean daily increase in yellowing scores of fresh broccoli heads following exposure to water for various duration-temperature combinations and then held 7 days at 20C. Rates of increase were calculated from the regression of daily yellowing scores.

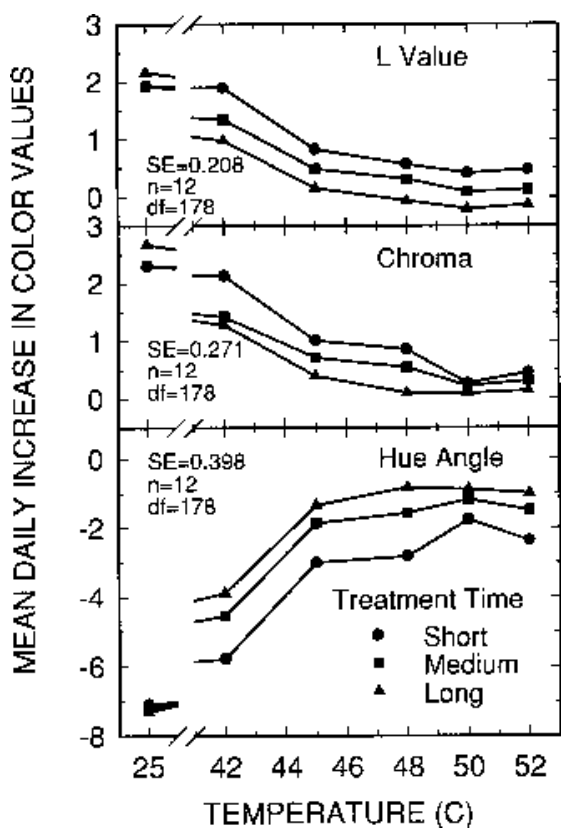

Fig. 2. Mean daily increase of the L value, chroma, and hue angle of fresh broccoli heads following exposure to water for various durationtemperature combinations and then held 7 days at $20 \mathrm{C}$. Rates of increase were calculated from the regression of daily measurements. 
hibiting yellowing of heads when broccoli was stored for 3 weeks at $0 \mathrm{C}$ before treatment (Fig. 4). Broccoli stored at $0 \mathrm{C}$ for 3 weeks yellowed more rapidly than fresh broccoli. Control heads exposed to $25 \mathrm{C}$ water turned yellow at a rate $60 \%$ greater than freshly harvested broccoli (Fig. 1), resulting in heads being yellow after $\approx 2$ days at $20 \mathrm{C}$. Heat treatments were less effective in delaying yellowing of stored broccoli than of fresh broccoli. However, the higher temperature treatments, $50 \mathrm{C}$ for 4 or 6 mins and 52C for 1 to 3 mins, inhibited yellowing so that the rate was similar to that for fresh broccoli. The effect of heat treatments on fresh weight loss, turgidity, decay, and odor was similar to that observed with freshly harvested broccoli.

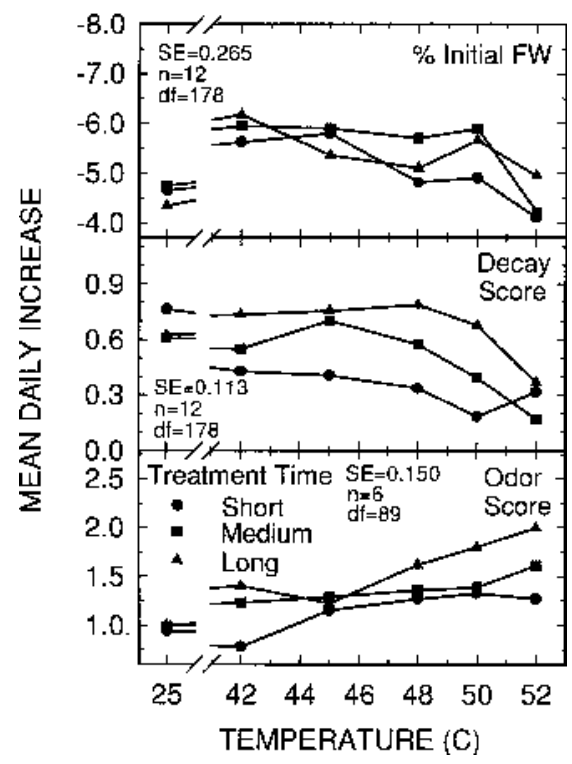

Fig. 3. Mean daily increase of fresh weight (FW), decay score, and odor score of fresh broccoli heads following exposure to water for various duration-temperature combinations and then held 7 days at 20C. Rates of increase were calculated from the regression of daily values.

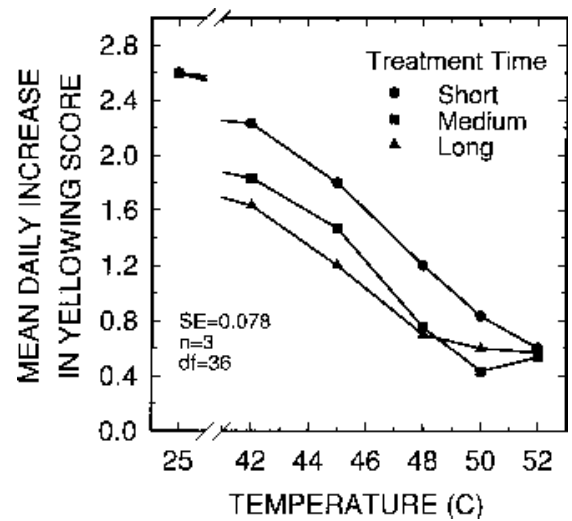

Fig. 4. Mean daily increase in yellowing scores of broccoli heads following exposure to water for various duration-temperature combinations and then held 7 days at 20C. Broccoli was held 3 weeks at $0 \mathrm{C}$ before treatment. Rates of increase were calculated from the regression of daily yellowing scores.

\section{Discussion}

Yellowing of broccoli flower buds occurs rapidly at ambient temperatures. At 20C, 'Cruiser' and 'Paragon' broccoli began to turn yellow in $\approx 3$ or 2.5 days, respectively. These rates of yellowing were similar to those reported in other studies (Kazami et al., 1991a; Wang and Hruschka, 1977). Yellowing also was reflected by a decline in the hue angle of the flower buds (Fig. 2C). Hue angle of broccoli held at $21 \mathrm{C}$ in air decreased from $\approx 128^{\circ}$ to $84^{\circ}$ in 7 days (Gnanasekharan et al., 1992), but that of 'Shogun' broccoli held at 20C in the dark decreased from $132^{\circ}$ to $112^{\circ}$ in 3 days (Tian et al., 1994). The increase in $\mathrm{L}$ value (Fig. 2A) and chroma (Fig. 2B) was less dramatic than the change in hue angle but was similar to that observed by Gnanasekharan et al. (1992).

Inhibition of yellowing caused by immersion in 42 to $52 \mathrm{C}$ water also was reported by Kazami et al. (1991a), who found that broccoli treated at $45 \mathrm{C}$ for $14 \mathrm{~min}$ remained green for 5 days when held at 20C. In addition, they reported that exposure to $48 \mathrm{C}$ for $\geq 10 \mathrm{~min}$ caused browning and shrinkage of the flower head after 2 days at 20C. Browning or shrinkage of broccoli was absent following exposure to $48 \mathrm{C}$ for $<8 \mathrm{~min}$. Immersion of broccoli in $52 \mathrm{C}$ water for $3 \mathrm{~min}$, however, altered the waxy bloom, making the flower buds appear dark green rather than the gray-green of nontreated broccoli. Heat treatments inhibit fruit yellowing, with storage at $>30 \mathrm{C}$ inhibiting yellowing of papaya (Carica papaya L.) (An and Paull, 1990). 'Breaker' tomatoes (Lycopersicon esculentum Mill.) held for 12 to $24 \mathrm{~h}$ at $43 \mathrm{C}$ remained green, failing to become red during 6 days of ripening at 20C (Hall, 1964). However, color development of some fruit, such as mangos (Mangifera indica L.), was stimulated by 2 days at 38C (McCollum et al., 1993).

The slight increase that I found in FW loss induced by some of the hot-water treatments was not observed by Kazami et al. (1991a), who found similar weight losses for heattreated broccoli and controls. Hot-water treatment does increase FW loss in some fruit (Hallman, 1991; Kerbel et al., 1987; McGuire, 1991).

Hot-water immersion can be an effective way to control decay of stored horticultural products (Couey, 1989). Hot-water dips that are effective in controlling decay of rose (Rosa hybida) or carnation (Dianthus carpophyllus L.) flowers included 50C for 20 to $40 \mathrm{sec}$, but a $60 \mathrm{C}$ dip for $60 \mathrm{sec}$ increased rates of decay (Elad and Volpin, 1991). Incidence of decay on broccoli responded similarly in that longer treatment times were less effective in reducing decay, but none of the treatments tested increased decay of flower buds beyond the level of the controls. Although decay of the stem was not rated, the cut surface of the stem appeared to have a greater incidence of shriveling and decay in some treatments than in the controls.

Off-odor induced by high temperaturelong duration, hot-water treatments appeared to be the first indication of physiological injury caused by the heat treatments. The nature of odor produced by heat-treated broccoli was different from the "rotten cabbage" odor induced by anaerobic stress (Forney et al., 1991), indicating that the induced volatiles were qualitatively and/or quantitatively different. Analysis of the composition of these induced volatiles could provide insights into the nature of physiological injury caused by heat treatments. Heat treatments also induced off-flavors in papaya (An and Paull, 1990) and caused a loss of fresh flavor in avocados (Perea americana Mill.) (Kerbel et al., 1987).

Hot-water treatments are effective in extending the shelf life of fresh broccoli. Of the treatments tested, immersion of broccoli in $50 \mathrm{C}$ water for $2 \mathrm{~min}$ seems to be most effective in reducing yellowing and decay while not inducing off-odors or weight loss. The injury that heat treatments cause on cut stem ends needs to be evaluated, but could be eliminated if stem ends are cut following treatment. This procedure would be practical if treatments were applied before packing or cutting into florets. In addition to extension of shelf life, hot water may be an effective technique to remove Lepidoptera larvae from broccoli, based on our observations and those of Kazami et al. (1991a).

\section{Literature Cited}

An, J.F. and R.E. Paull. 1990. Storage temperature and ethylene influence on ripening of papaya fruit. J. Amer. Soc. Hort. Sci. 115:949-953.

Barth, M.M., E.L. Kerbel, S. Broussard, and S.J. Schmidt. 1993. Modified atmosphere packaging protects market quality in broccoli spears under ambient temperature storage. J. Food Sci. 58(5):1070-1072.

Couey, H.M. 1989. Heat treatment for control of postharvest diseases and insect pests of fruits. HortScience 24:198-202.

Elad, Y. and H. Volpin. 1991. Heat treatment for the control of rose and carnation grey mould (Botrytis cinerea). Plant Pathol. 40:278-286.

Forney, C.F., J.P. Mattheis, and R.K. Austin. 1991. Volatile compounds produced by broccoli under anaerobic conditions. J. Agr. Food Chem. 39(12):2257-2259.

Gnanasekharan, V., R.L. Shewfelt, and M.S. Chinnan. 1992. Detection of color changes in green vegetables. J. Food Sci. 57(1):149-154.

Hall, C.B. 1964. The effect of short periods of high temperature on the ripening of detached tomato fruits. Proc. Amer. Soc. Hort. Sci. 84:501-506.

Hallman, G.J. 1991. Quality of carambolas subjected to postharvest hot water immersion and vapor heat treatments. HortScience 26:286-287.

Kazami, D., T. Sato, H. Nakagawa, and N. Ogura. 1991a. Effect of pre-storage hot water dipping of broccoli heads on shelf life and quality during storage (in Japanese, English summary). Nippon Nogeikagaku Kaishi 65(1):19-26.

Kazami, D., T. Sato, H. Nakagawa, and N. Ogura. 1991b. Effect of pre-storage hot water dipping of broccoli heads on soluble protein, free amino acid contents and protease activities during storage (in Japanese, English summary). Nippon Nogeikagaku Kaishi 65(1):27-33.

Kerbel, E.L., F.G. Mitchell, and G. Mayer. 1987. Effect of postharvest heat treatments for insect control on the quality and market life of avocados. HortScience 22:92-94. 
Lipton, W.J. and C.M. Harris. 1974. Controlled atmosphere effects on market quality of stored broccoli (Brassica oleracea L., Italica group). J. Amer. Soc. Hort. Sci. 99:200-205.

McCollum, T.G., S. D'Aquino, and R.E. McDonald. 1993. Heat treatment inhibits mango chilling injury. HortScience 28:197-198.

McGuire, R.G. 1991. Concomitant decay reductions when mangoes are treated with heat to control infestations of Caribbean fruit flies. Plant Dis. 75:946-949.

Paull, R.E. 1990. Postharvest heat treatments and fruit ripening. Postharvest News \& Info. 1(5):355-363

Payne, R.W., P.W. Lane, P.G.N. Digby, S.A. Harding, P.K. Leech, G.W. Morgan, A.D. Todd, R. Thompson, G.T. Wilson, S.J. Welham, and R.P. White. 1993. Genstat 5 reference manual. Clarendon Press, Oxford, U.K.

Ryall, A.L. and W.J. Lipton. 1979. Handling, trans- portation and storage of fruits and vegetables. vol. 1. Vegetables and melons. 2nd ed. AVI, Westport, Conn.

Tian, M.S., C.G. Downs, R.E. Lill, and G.A. King. 1994. A role for ethylene in the yellowing of broccoli after harvest. J. Amer. Soc. Hort. Sci. 119:276-281.

Wang, C.Y. and H.W. Hruschka. 1977. Quality maintenance in polyethylene-packaged broccoli. U.S. Dept. Agr. Mktg. Res. Rpt. 1085. 